\title{
Impact of process parameters and design options on heat leaks of straight cryogenic distribution lines
}

\author{
P. Duda, M. Chorowski, and J. Polinski \\ Faculty of Mechanical and Power Engineering, Wroclaw University of Technology, \\ Wyb. Wyspianskiego 27, Wroclaw 50-370, Poland \\ (Received 9 July 2016; published 27 March 2017)
}

\begin{abstract}
The Future Circular Collider (FCC) accelerator will require a helium distribution system that will exceed the presently exploited transfer lines by almost 1 order of magnitude. The helium transfer line will contain five process pipes protected against heat leaks by a common thermal shield. The design pressure of the FCC process pipe with supercritical helium will be equal to $5.0 \mathrm{MPa}$, significantly exceeding the 2.0 MPa value in the present, state-of-art transfer lines. The increase of the design pressure requires construction changes to be introduced to the support system, the vacuum barriers and the compensation bellows. This will influence heat flows to the helium. The paper analyses the impact of the increased design pressure on the heat flow. The paper also offers a discussion of the design modifications to the compensation system, including the replacement of stainless steel with Invar ${ }^{\circledR}$-aimed at mitigating the pressure increase.
\end{abstract}

DOI: 10.1103/PhysRevAccelBeams.20.033202

\section{INTRODUCTION}

The international Future Circular Collider (FCC) study has been launched by CERN as host institute, to design an energy frontier hadron collider (FCC-hh) in a new $80-100 \mathrm{~km}$ quasicircular tunnel with a center-of-mass energy of about $100 \mathrm{TeV}$, an order of magnitude above the LHC's, as a long-term goal [1]. The FCC study also includes the design of a 90-350 GeV high-luminosity lepton collider (FCC-ee) fitting the same tunnel, serving as Higgs, top and Z factory, as a potential intermediate step, as well as an electron-proton collider option (FCC-he) [2,3]. The main technological challenge of the hadron collider is the high-field superconducting magnet system which requires cooling along most of the machine circumference at liquid helium temperature; the option is still open between normal helium at $4.5 \mathrm{~K}$ and superfluid helium at $1.9 \mathrm{~K}$, depending on the choice of magnet technology and on the cryopumping requirements for the beam vacuum [4]. Significant growth in scale entails numerous problems, many of which have never been tackled before. One such problem is a considerable growth in the length of cryogenic distribution lines, which will be used to transport liquid helium from cryoplants to superconducting magnets installed in the tunnel. The maximum length for a distribution line in the LHC accelerator is $3.3 \mathrm{~km}$. As far as the FCC study is considered, two solutions are presently proposed to the problem of distributing helium to superconducting magnets. The first solution is to locate ten cryoplants along

Published by the American Physical Society under the terms of the Creative Commons Attribution 3.0 License. Further distribution of this work must maintain attribution to the author(s) and the published article's title, journal citation, and DOI. the accelerator. In such a case the helium distribution system will require two lines $9.4 \mathrm{~km}$ in length and eight lines $8.4 \mathrm{~km}$ in length. The alternative solution is installation of 20 cryoplants, thus the magnets would be supplied from lines of between 4 and $6.5 \mathrm{~km}$ in length. Figure 1 shows the schematic diagrams of the two proposed helium distribution networks.

In both solutions, however, the lengths of the cryogenic distribution lines greatly exceed the lengths that are currently technologically feasible. Constructing cryogenic lines of great lengths will entail two major problems. The first one is related to the loss of pressure as the gas flows along the pipeline. The second problem is caused by the significant amount of heat that will leak in the helium on its way along a distribution line of such length. Heat leaks are particularly important in the process pipe used to cool the radiation shield, as heat flow per one meter of length is the greatest at that point. To remove such an amount of heat, the gas flowing along the pipe cools the radiation shield must have a significant mass flow rate. The mass flow rate may be increased by raising either gas flow velocity or gas pressure. Raising gas flow velocity results in increased flow resistance and losses due to pressure drop. Therefore, an attempt was made for the long helium cryogenic lines in the FCC study to analyze the influence of pressure buildup on the major structural nodes of the pipeline and on the losses related to heat leaks.

\section{THE INFLUENCE OF PRESSURE BUILDUP ON HEAT LEAKS IN A MULTICHANNEL CRYOGENIC TRANSFER LINE}

The majority of the currently used multichannel cryogenic transfer lines have a modular and uniform structure that consists of a number of major structural nodes. 

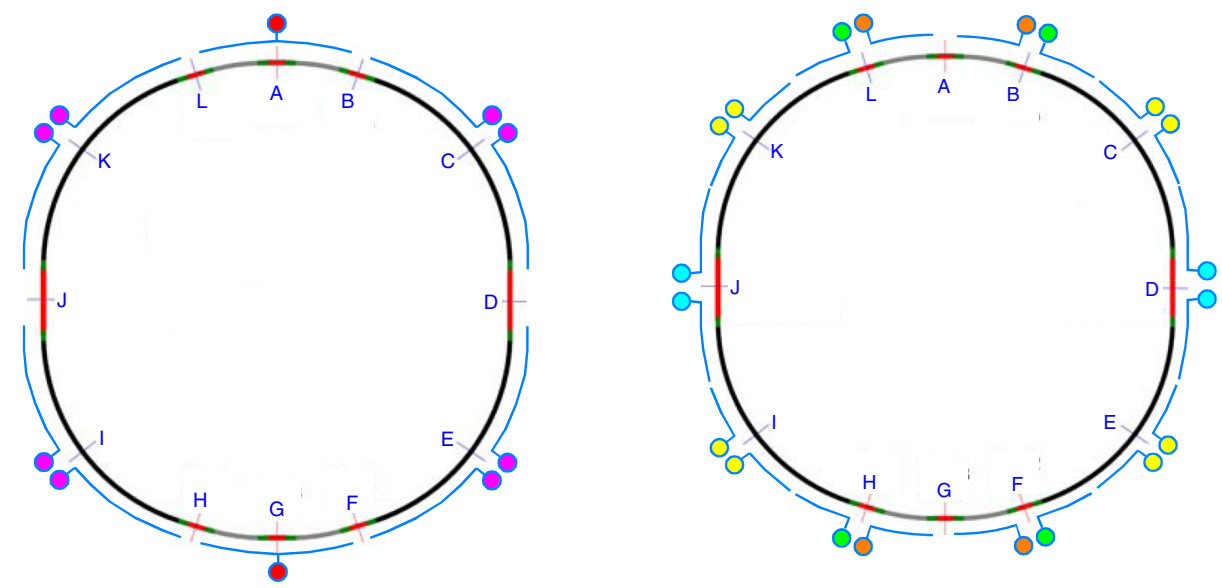

\begin{tabular}{|c|c|}
\hline Cryoplant & $\begin{array}{c}\text { L } \\
\text { distribution } \\
\text { km }\end{array}$ \\
\hline$\bigcirc$ & $2 \times 4.7=9.4$ \\
\hline$O$ & 8.4 \\
\hline
\end{tabular}

\begin{tabular}{|c|c|c|c|}
\hline Cryoplant & $\begin{array}{c}\mathrm{L} \\
\text { distribution } \\
\mathrm{km}\end{array}$ & Cryoplant & $\begin{array}{c}\mathrm{L} \\
\text { distribution } \\
\mathrm{km}\end{array}$ \\
\hline $\mathrm{O}$ & 4.7 & $\bigcirc$ & 4 \\
\hline $\mathrm{O}$ & 5.1 & $\bigcirc$ & 6.5 \\
\hline
\end{tabular}

FIG. 1. Schematic diagram of the two proposed helium distribution networks for the FCC study [5].

Cryogen is transferred through several so-called process pipes made of stainless steel. Stainless steel has high mechanical strength at low temperatures and low coefficient of thermal conductivity. To protect the process pipes against heat radiation, they are placed inside a thermal shield whose temperature is between the temperature of the process pipes and the ambient temperature. To avoid thermal gradient on the surface of the radiation shield, the shield is made of materials that have high heat conductivity. On the outside, the pipeline is covered with a vacuum shell, which maintains the thermal insulation vacuum around the process pipes and thermal shield. Both the process pipes and the thermal shield rest on supports, which define their position and protect them from coming into contact with each other. The only exception is the process pipe which collects the heat that reaches the thermal shield as a result of radiation. The pipe that cools the thermal shield ought to remain in such a connection with the shield that heat flow is possible without significant thermal gradients.

For ease of transportation and assembly, cryogenic transfer lines are manufactured as a modular system, with the length of a single module usually kept below $12 \mathrm{~m}$. Systems made of stainless steel must be equipped with elements that allow compensating for negative thermal expansion. Otherwise, when the system is cooled, the stresses in the process pipes would exceed permissible values and the forces acting on the supports would also reach considerable values.

To examine the influence that the raised design pressure has on heat leaks to the process pipes, calculations have been made for two straight $50 \mathrm{~m}$ sections of a multichannel pipeline of identical diameters. The design of the test sections was based on the most commonly used design solutions mentioned above. The schematic representation of the test sections is shown in Fig. 2. Both ends of the test sections are equipped with vacuum barriers that simultaneously function as strong fixed supports (strong supports which are fixed).

The dimensions of the process pipes as well as transferred helium parameters and process pipes design parameters are identical to the parameters planned in the FCC study and are shown in Table I. The parentheses contain the proposed raised pressure values that would result in the increased mass flow rate of the transferred helium. Figure 3 shows the denotations of the process pipes and their location on the cross section of the distribution line.

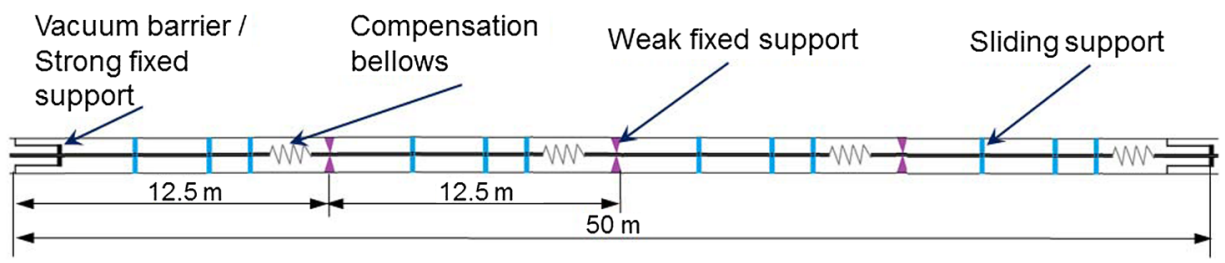

FIG. 2. Schematic view of a $50 \mathrm{~m}$ section of a cryogenic transfer line based on standard design solutions. 
TABLE I. Description of the functions and the design parameters of the process pipes.

\begin{tabular}{|c|c|c|c|c|c|c|}
\hline & & & Nom. & Nom. & Design & Test \\
\hline Process pipe & Function & $\mathrm{DN}[\mathrm{mm}]$ & $\mathrm{T}[\mathrm{K}]$ & $\mathrm{P}_{N}[\mathrm{MPa}]$ & $\mathrm{P}_{D}[\mathrm{MPa}]$ & $\mathrm{P}_{T}[\mathrm{MPa}]$ \\
\hline B & Pumping line & 250 & 4 & 0.05 & 0.4 & 0.6 \\
\hline $\mathrm{C}$ & SHe supply & 80 & 4.6 & 0.3 & 2.0 & 2.9 \\
\hline $\mathrm{D}$ & Quench line and current lead He supply & 200 & 40 & 0.13 & 2.0 & 2.9 \\
\hline $\mathrm{E}$ & Thermal shield and beam screen He supply & 240 & 40 & $2.0(5.0)$ & $2.0(5.0)$ & $2.9(7.15)$ \\
\hline $\mathrm{F}$ & Thermal shield and beam screen He return & 240 & 60 & $1.5(4.5)$ & $2.0(5.0)$ & $2.9(7.15)$ \\
\hline
\end{tabular}

Figure 3 shows the design of two uniform modules that are part of the $50 \mathrm{~m}$ test sections. It also shows a design concept for each of the supports required in the analyzed pipeline sections.

Each of the pipeline modules is equipped with compensation bellows installed on the process pipes. As a single module is $12 \mathrm{~m}$ in length, a wide variety of typically sized, commercially available compensation bellows could be used. Each module also has a weak fixed support (weak support which is fixed), which ensures proper operation of the compensation bellows by allowing each of the compensation bellows installed along the process pipe to compensate only the shrinkage of the 12-meter section of the pipe. Without the weak fixed supports, the compensation bellows may undergo excessive deformation and become damaged. The number of sliding supports is defined by the manufacturer of the compensation bellows as well as by permissible deflection. Figure 4 is a diagram of a proper support structure for the compensation bellows.

Using compensation bellows entails the occurrence of additional forces $\left(F_{T S}\right)$ related to the elasticity and strain of the bellows, Eq. (1). Another force $\left(F_{P}\right)$ generated by the compensation bellows is dependent on the pressure inside the bellows and on its effective cross-sectional area, Eq. (2). During operation in nominal conditions both forces have opposite senses and therefore the force exerted by the bellows on the fixed supports is the difference of the force and the pressure and of the force and the strain $\left(F_{N P}\right)$, Eq. (3):

$$
F_{T S}=\Delta L C_{\delta} \text {-depends on nominal temperature }
$$

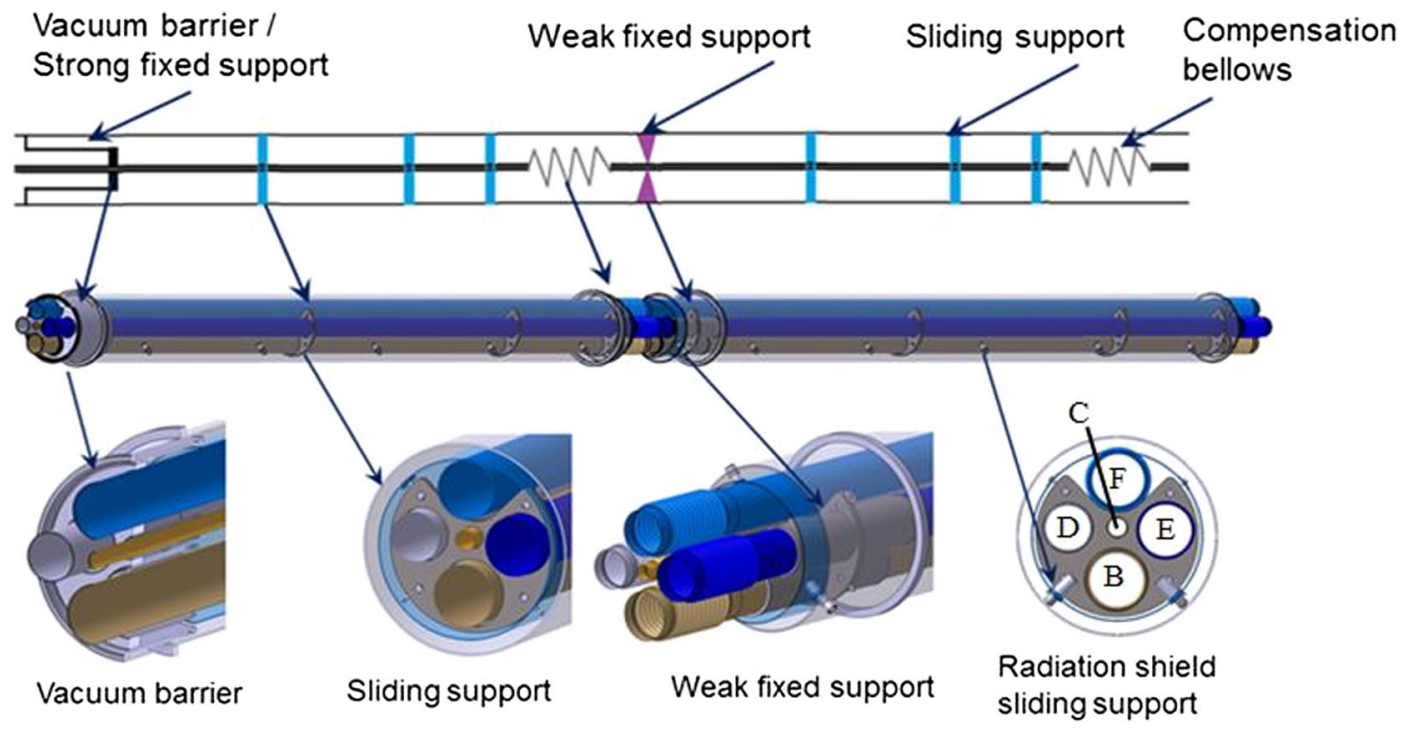

FIG. 3. Schematic view of two $12 \mathrm{~m}$ modules included in the $50 \mathrm{~m}$ section of a cryogenic transfer line.

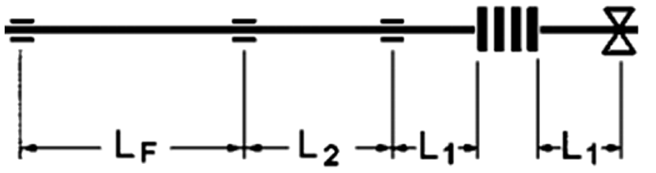

$\mathrm{L}_{1}=3 \mathrm{DN}-$ for axial expansion joints
$\mathrm{L}_{2}=0.5 \mathrm{~L}_{\mathrm{F}}$
$\mathrm{L}_{\mathrm{F}}-$ depends on the accepted deflection
and the risk of pipe buckling

FIG. 4. Schematic diagram of proper supports for the compensation bellows [6]. 
TABLE II. Determining the forces acting on the supports and generated by the compensation bellows.

\begin{tabular}{|c|c|c|c|c|c|c|c|c|c|c|c|}
\hline \multirow[b]{2}{*}{$\begin{array}{l}\text { Process } \\
\text { pipe }\end{array}$} & \multicolumn{3}{|c|}{ Parameters of bellows } & \multicolumn{4}{|c|}{ Parameters of process pipes } & \multicolumn{4}{|c|}{ Determination of forces } \\
\hline & $\begin{array}{c}2 \delta \\
{[\mathrm{mm}]}\end{array}$ & $\begin{array}{c}\mathrm{A} \\
{\left[\mathrm{cm}^{2}\right]}\end{array}$ & $\begin{array}{c}\mathrm{C}_{\delta} \\
{[\mathrm{N} / \mathrm{mm}]}\end{array}$ & $\begin{array}{c}\mathrm{P}_{D} \\
{[\mathrm{MPa}]}\end{array}$ & $\begin{array}{c}\mathrm{P}_{T} \\
{[\mathrm{MPa}]}\end{array}$ & $\begin{array}{c}\Delta \mathrm{L} \\
{[\mathrm{mm}]}\end{array}$ & $\begin{array}{c}\mathrm{F}_{P} \\
{[\mathrm{kN}]}\end{array}$ & $\begin{array}{c}\mathrm{F}_{\mathrm{TS}} \\
{[\mathrm{kN}]}\end{array}$ & $\begin{array}{l}\mathrm{F}_{\mathrm{NP}} \\
{[\mathrm{kN}]}\end{array}$ & $\begin{array}{c}\mathrm{F}_{\text {Test2.0 MPa }} \\
{[\mathrm{kN}]}\end{array}$ & $\begin{array}{c}\mathrm{F}_{\text {Test5.0 }} \mathrm{MPa} \\
{[\mathrm{kN}]}\end{array}$ \\
\hline B DN250 & 79 & 695 & 370 & 0.4 & 0.57 & 37.5 & -3.5 & 6.5 & 3.0 & -40 & -40 \\
\hline C DN80 & 42 & 92.5 & 222 & 2.0 & 2.9 & 37.5 & -2.8 & 3.9 & 1.1 & -26 & -26 \\
\hline D DN200 & 52 & 443 & 428 & 2.0 & 2.9 & 37.5 & -5.8 & 7.5 & 1.7 & -127 & -127 \\
\hline E DN240 & 79 & 679 & 390 & $2.0(5.0)$ & $2.9(7.15)$ & 37.5 & -136 & 6.8 & -129 & -194 & -486 \\
\hline F DN240 & 79 & 679 & 390 & $2.0(5.0)$ & $2.9(7.15)$ & 37.5 & -102 & 6.8 & -95 & -194 & -486 \\
\hline
\end{tabular}

$F_{P}=A_{E} P$-depends on pressure inside process pipe

$$
F_{N P}=F_{P}-F_{T S} \text { for nominal parameters }
$$

where $F_{T S}$ is the force generated by the strain of the bellows, $\Delta L$ is the displacement of the bellows, $\mathrm{C}_{\delta}$ is the spring constant of the bellows, $F_{P}$ is the force generated by the pressure acting on the bellows effective cross-sectional area, $A_{E}$ effective cross-sectional area of the bellows, $P$ is the pressure inside the bellows, $F_{N P}$ is the force generated by the bellows during nominal operation.

The worst load scenario is a pressure test, as it is performed when the process pipes have temperature equal to ambient temperature and no force due to bellows strain occurs. Test pressure is higher than nominal pressure and hence the value of the force acting on the supports is highest. Table II shows the forces acting on strong fixed supports, determined for individual process pipes.

Although permissible stress values are higher for test parameters than for design parameters, the forces in a pressure test constitute the highest load on fixed supports and determine their geometry. In the case of increased design pressure (5.0 MPa), the sum of the forces acting on the fixed support during the pressure test is twice as large as in the case of standard pressure (2.0 MPa). Knowing the loads taken by the supports, their geometry was designed in such a way that the allowable stress values are exceeded neither in design conditions nor in test conditions. For both cases, first, the geometry of the supports used in the 50-meter section of the pipeline was designed and subsequently heat leaks into each of the process pipes due to heat conduction were determined. Table III shows the values of heat flows through the supports. In the case of process pipe $F$, a negative value of heat flow was received for the sliding support, as the heat flowing through the sliding support to the other process pipes is received from the radiation shield and pipe $F$ is a pipe that thermalizes the radiation shield.

The determined heat flows lead to an observation that the twofold increase in the force acting on the strong fixed supports increases of heat leaks by $13 \%-20 \%$. However, a significant increase in the forces acting on the supports may cause construction problems, as it requires using plates and pipes of considerable thickness. Introducing compensation bellows to the cryogenic line constrains the designer to provide additional supports in order to maintain mechanical stability of the process pipes. Increasing the number of supports and their types causes increased heat leaks into the pipeline and leaves the line prone to failure. Moreover, analysis of the pipelines constructed so far suggests that compensation bellows are the most failure-prone element of a cryogenic line [7].

\section{MODEL OF A CRYOGENIC LINE WITH PROCESS PIPES MADE OF INVAR ${ }^{\circledR}$}

As described above, using compensation bellows has a negative effect on heat leaks into process pipes and on the structure of the cryogenic transfer line. Therefore, designing a cryogenic transfer line that would not comprise

TABLE III. The determined values of heat flows for both of the analyzed cases.

\begin{tabular}{|c|c|c|c|c|c|}
\hline \multirow[b]{2}{*}{ Process pipe } & \multicolumn{2}{|c|}{$\begin{array}{l}\text { Vacuum } \\
\text { barrier (x2) }\end{array}$} & \multirow{2}{*}{$\begin{array}{c}\begin{array}{c}\text { Sliding } \\
\text { support (x12) }\end{array} \\
\mathrm{Q}_{\mathrm{SS}}[\mathrm{W}] \\
\end{array}$} & \multirow{2}{*}{$\begin{array}{r}\text { Weak fixed } \\
\text { support (x3) }\end{array}$} & \multirow{2}{*}{$\begin{array}{c}\begin{array}{c}\text { Radiation shield } \\
\text { sliding support }(\mathrm{x} 20)\end{array} \\
\mathrm{Q}_{\mathrm{RSS}}[\mathrm{W}]\end{array}$} \\
\hline & $\mathrm{Q}_{\mathrm{VB} 2.0 \mathrm{MPa}}[\mathrm{W}]$ & $\mathrm{Q}_{\mathrm{VB} 5.0 \mathrm{MPa}}[\mathrm{W}]$ & & & \\
\hline $\mathrm{B} \mathrm{T}_{N}=4 \mathrm{~K} \mathrm{DN} 250$ & 1.21 & 1.45 & 0.24 & 0.50 & $\cdots$ \\
\hline $\mathrm{C} \mathrm{T}_{N}=4.6 \mathrm{~K} \mathrm{DN80}$ & 0.20 & 0.30 & 0.33 & 0.07 & $\cdots$ \\
\hline $\mathrm{D} \mathrm{T}_{N}=40 \mathrm{~K} \mathrm{DN} 200$ & 1.28 & 1.45 & 0.03 & 0.11 & $\ldots$ \\
\hline $\mathrm{E} \mathrm{T}_{N}=40 \mathrm{~K} \mathrm{DN} 240$ & 1.41 & 2.13 & 0.03 & 0.98 & $\cdots$ \\
\hline $\mathrm{F} \mathrm{T}_{N}=60 \mathrm{~K} \mathrm{DN} 240$ & 33.7 & 39.7 & -0.63 & 7.90 & 3.1 \\
\hline
\end{tabular}



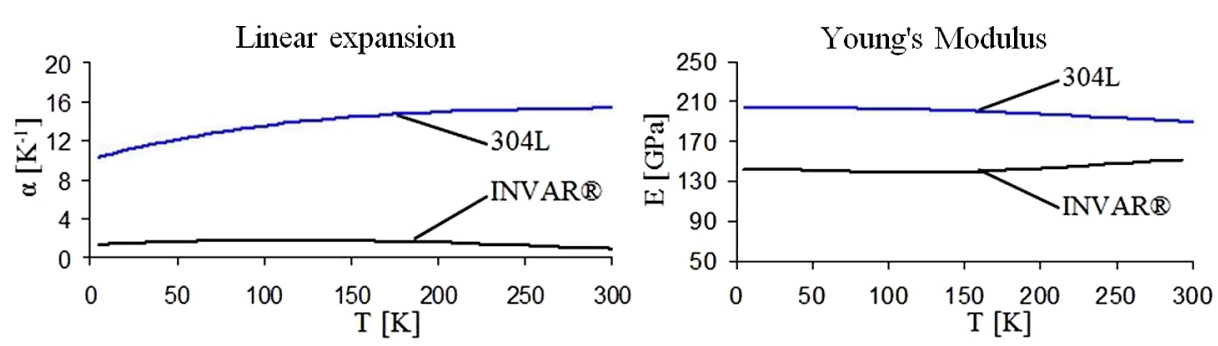

FIG. 5. Comparison of the properties of stainless steel 304L and Invar ${ }^{\circledR}$ [9].

compensation bellows seems rational. Such a line can be constructed by two methods: either by compensating with the shape of process pipes or by making process pipes from a material characterized by low coefficient of thermal expansion [8]. Compensation with shape, however, requires a sufficient amount of free space and frequently entails the need to build a pipeline of a complicated shape, thus creating more problems with design and construction. Consequently, making pipes of Invar ${ }^{\circledR}$ seems an attractive alternative, as the material has a low coefficient of thermal expansion and acceptable mechanical properties. Figure 5 shows the comparison of the coefficient of thermal expansion and Young's modulus for stainless steel $304 \mathrm{~L}$ and Invar ${ }^{\circledR}$.

As compared to stainless steel, Invar ${ }^{\circledR}$ has an almost 10 times lower coefficient of linear thermal expansion, enabling the construction of cryogenic pipelines without compensation bellows. Until recently, producing process pipes of Invar ${ }^{\circledR}$ remained an unpopular solution, as making durable and hermetic connections between Invar ${ }^{\circledR}$ and stainless steel was problematic. However, great progress is currently seen in the technology. The first cryogenic transfer lines with Invar $^{\circledR}$ process pipes have been already constructed [10]. A design study was also performed for superconducting cryogenic power transmission lines, in which helium channels are made of Invar ${ }^{\circledR}$ [11]. In order to enable comparison between a system with Invar $^{\circledR}$ process pipes and the previously analyzed system with stainless steel process pipes, further analysis was performed on a pipeline section of identical length as in previous cases. Due to the absence of compensation bellows, supports in a pipeline with Invar ${ }^{\circledR}$ process pipes are fewer in number and type. Figure 6 shows a schematic diagram of a $50 \mathrm{~m}$ straight section of a pipeline with Invar ${ }^{\circledR}$ process pipes.

The pipeline shown in Fig. 6 has sliding supports only and two vacuum barriers on both ends, which offer an additional function as strong fixed supports. The arrangement of sliding supports has been decided on the basis of the assumed deflection of the process pipes. The structure of the sliding supports is identical in both cases to facilitate the comparison between the models with stainless steel process pipes and the model with Invar ${ }^{\circledR}$ process pipes. As the process pipes in the analyzed case have different diameters and carry cryogens of different density, when determining maximum distances between the supports consideration should be given to all process pipes. Equation (4) represents the method to calculate the distance between sliding supports:

$$
x=\min \left|\sqrt[4]{\frac{87 f E\left(D_{i}^{4}-d_{i}^{4}\right)}{20 g\left[\rho_{I N V}\left(D_{i}^{2}-d_{i}^{2}\right)+\rho_{H e} d_{i}^{2}\right]}}\right|_{i}^{1},
$$

where $x$ is the allowable distance between sliding supports, $f$ is the allowable value of process pipe deflection, $E$ is the Young's modulus, $D_{i}$ is the outside diameter of the i process pipe, $d_{i}$ is the inside diameter of the i process pipe, $\rho_{I N V}$ is the Invar ${ }^{\circledR}$ density, $\rho_{\mathrm{He}}$ is the density of helium transferred through the i process pipe, and $g$ is the acceleration of gravity.

Equation (4) shows that for a straight section of the pipeline, the allowable distance between the supports has a negligible dependency on the pressure inside the process pipes. Increasing pressure of the transferred cryogen entails an increase in cryogen density and also necessitates the use of process pipes with thicker walls. For further analysis, the design pressure in the loop that cools the radiation shield (pipes $E$ and $F$ ) was assumed to be $5.0 \mathrm{MPa}$.

As Invar ${ }^{\circledR}$ does not have a zero coefficient of linear thermal expansion, during the process of pipeline cooling the fixed supports will take loads that result from Hooke's law, Eq. (5). Table IV shows the values of the forces calculated for each of the process pipes:

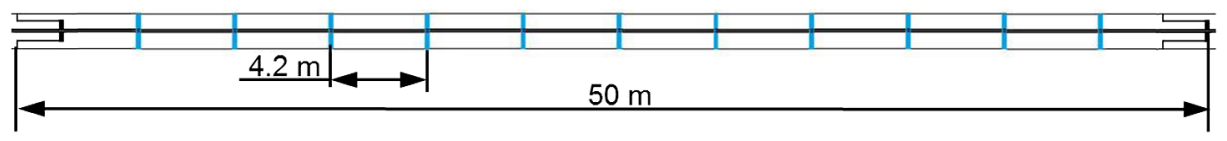

FIG. 6. Schematic diagram of a $50 \mathrm{~m}$ straight section of a cryogenic distribution line with Invar ${ }^{\circledR}$ process pipes. 
TABLE IV. Calculating the forces acting on strong fixed supports for Invar ${ }^{\circledR}$ process pipes.

\begin{tabular}{lcccccc}
\hline \hline $\begin{array}{l}\text { Process } \\
\text { pipe }\end{array}$ & $\begin{array}{c}\mathrm{T} \\
{[\mathrm{K}]}\end{array}$ & $\begin{array}{c}\delta \\
{[\mathrm{mm}]}\end{array}$ & $\begin{array}{c}\mathrm{L} \\
{[\mathrm{m}]}\end{array}$ & $\begin{array}{c}\mathrm{A} \\
{\left[\mathrm{mm}^{2}\right]}\end{array}$ & $\begin{array}{c}\mathrm{E} \\
{[\mathrm{GPa}]}\end{array}$ & $\begin{array}{c}\mathrm{F} \\
{[\mathrm{kN}]}\end{array}$ \\
\hline B DN250 & 4 & 20 & 50 & 1703 & 141.7 & 96.5 \\
C DN80 & 4.6 & 20 & 50 & 546 & 141.7 & 30.94 \\
D DN200 & 40 & 20 & 50 & 1836 & 141.7 & 104.0 \\
E DN240 & 40 & 20 & 50 & 2384 & 141.7 & 135.1 \\
F DN240 & 60 & 20 & 50 & 2384 & 140.8 & 134.3 \\
\hline \hline
\end{tabular}

TABLE V. heat flows reaching each of the process pipes through a given type of support.

\begin{tabular}{|c|c|c|c|}
\hline & $\begin{array}{l}\text { Vacuum } \\
\text { barrier } \\
(\mathrm{x} 2)\end{array}$ & $\begin{array}{l}\text { Sliding } \\
\text { support } \\
\text { (x11) }\end{array}$ & $\begin{array}{c}\text { Radiation } \\
\text { shield sliding } \\
\text { support (x20) }\end{array}$ \\
\hline Process pipe & $\mathrm{Q}_{\mathrm{VB}}[\mathrm{W}]$ & $\mathrm{Q}_{\mathrm{SS}}[\mathrm{W}]$ & $\mathrm{Q}_{\mathrm{RSS}}[\mathrm{W}]$ \\
\hline $\mathrm{B} \mathrm{T}_{N}=4 \mathrm{~K} \mathrm{DN} 250$ & 1.17 & 0.24 & . \\
\hline $\mathrm{C} \mathrm{T}_{N}=4.6 \mathrm{~K} \mathrm{DN80}$ & 0.19 & 0.33 & \\
\hline $\mathrm{D} \mathrm{T}_{N}=40 \mathrm{~K} \mathrm{DN} 200$ & 1.21 & 0.03 & \\
\hline $\mathrm{E} \mathrm{T}_{N}=40 \mathrm{~K} \mathrm{DN} 240$ & 1.33 & 0.03 & $\cdots$ \\
\hline $\mathrm{F} \mathrm{T}_{N}=60 \mathrm{~K} \mathrm{DN} 240$ & 27.42 & -0.63 & 3.1 \\
\hline
\end{tabular}

$$
F=A E \frac{\delta l}{L}
$$

where $F$ is the force acting on fixed supports, $A$ is the crosssectional area of the process pipe, and $\delta l$ is the thermal shrinkage of the pipe length $L$.

Comparing the sums of the forces acting on strong fixed supports in all three analyzed cases shows that the smallest $(501 \mathrm{kN})$ sum of forces is generated by the pipes made of Invar $^{\circledR}$. This may be comparable with the solution based on stainless steel process pipes and compensation bellows for design pressure 2.0 MPa $(581 \mathrm{kN})$. The solution based on compensation bellows and raised pressure generates the greatest forces $(1163 \mathrm{kN})$.

Knowing the forces acting on the fixed supports allowed us to adjust the support geometry to the loads and to calculate heat leaks into process pipes due to heat conduction. Finding the necessary amount of sliding supports per the 50-meter pipeline section was followed by calculating total heat flows reaching each of the process pipes. Table V shows the heat flows reaching each of the process pipes through a given type of support.

\section{CONCLUSIONS}

The analysis of the 50-meter section of the cryogenic transfer line comprising stainless steel process pipes and compensation bellows allows a conclusion that the increase in the pressure in the thermal shield cooling circuit from 2.0 to 5.0 MPa doubles the force values that act on the supports. As expected, the increase of pressure also increases the heat
TABLE VI. Comparison of total heat leaks through the supports to each of the process pipes.

\begin{tabular}{|c|c|c|c|c|}
\hline Process pipe & $\begin{array}{c}\mathrm{T} \\
{[\mathrm{K}]}\end{array}$ & $\begin{array}{c}\text { QSteel2.0MPa }_{\text {[W] }} \\
\text { [ }\end{array}$ & $\begin{array}{c}\mathrm{Q}_{\text {Steel5.0 MPa }} \\
{[\mathrm{W}]}\end{array}$ & $\begin{array}{c}\mathrm{QINV5.0} \mathrm{MPa} \\
{[\mathrm{W}]}\end{array}$ \\
\hline $\mathrm{B} \mathrm{T}_{N}=4 \mathrm{~K} \mathrm{DN} 250$ & 4 & 6.8 & 7.4 & 5.0 \\
\hline $\mathrm{C} \mathrm{T}_{N}=4.6 \mathrm{~K} \mathrm{DN} 80$ & 4.6 & 4.6 & 4.6 & 4.0 \\
\hline $\mathrm{D} \mathrm{T}_{N}=40 \mathrm{~K}$ DN200 & 40 & 3.2 & 3.7 & 2.8 \\
\hline $\mathrm{E} \mathrm{T}_{N}=40 \mathrm{~K} \mathrm{DN} 240$ & 40 & 3.5 & 4.9 & 3.0 \\
\hline $\mathrm{F} \mathrm{T}_{N}=60 \mathrm{~K} \mathrm{DN} 240$ & 60 & 146 & 158 & 110 \\
\hline
\end{tabular}

leaks to the process pipes, but the increase of heat leaks is lower than 20\%. In the case of cryogenic pipelines comprising stainless steel process pipes, the key elements are compensation bellows. The usage of compensation bellows determines the number of pipeline supports and introduces additional forces that appear due to pressure.

In comparison with stainless steel process pipes, the model comprising Invar ${ }^{\circledR}$ process pipes with $5.0 \mathrm{MPa}$ pressure in the thermal shield circuit had the smallest forces generated by the process pipes on the vacuum barriers. This solution also had the smallest number of supports and allowed us to obtain the lowest values for heat leaks through the supports to the process pipes. Table VI shows the comparison of the total heat leaks to each of the process pipes through all the supports used in a given design.

The most reliable transfer line is without bellows, which can be produced by using the Invar ${ }^{\circledR}$ material [12]. Using a design without compensation bellows allows not only to limit heat leaks but also to reduce the failure rate of the pipeline, as the bellows are the most failure-prone element of a cryogenic line [7]. Moreover, each compensation bellows requires an additional weld on the process pipe and the weld seam also becomes a potential failure spot. Although the probability of failure due to weld rapture is lower than the probability of compensation bellows rapture [13], reducing the number of welds has a significant role in reducing the failure rate of cryogenic transfer lines. The cryogen supply lines constructed for the FCC study will be mostly straight lines. Hence, the analysis here presented was performed using straight pipeline sections as an example and does not reflect the influence of pipe knees on mechanical loads in process pipes, while this factor may prove to be of key importance in the case of complicated structures.

The obtained results indicate that using cryogenic transfer lines with Invar ${ }^{\circledR}$ process pipes rather than stainless steel pipes permits raising the design pressure with only a slight increase in heat flows. Such structures allow to reduce the drop in the pressure of the transferred cryogen and hence prove advantageous in the construction of long and straight transfer lines, which will be required in the FCC study. The two other important advantages consist in lowering failure probability and reducing the number of welded connections 
used in the assembly process. This study shows that using cryogenic transfer lines comprising Invar ${ }^{\circledR}$ process pipes offers the possibility to apply higher design pressure and at the same time to increase the mechanical stability of the pipeline, as no compensation bellows need to be used in the process pipes.

\section{ACKNOWLEDGMENT}

The work has been supported by CERN in frame of FCC-GOV-CC-0036 Agreement and statutory funds. The authors would like to thank Laurent Tavian from CERN for fruitful discussions.

[1] A. Niemi, A. Apollonio, J. Gutleber, P. Sollander, J.-P. Penttinen, and S. Virtanen, Availability modeling approach for future circular colliders based on the LHC operation experience, Phys. Rev. Accel. Beams 19, 121003 (2016).

[2] M. Benedikt and F. Zimmermann, Towards future circular colliders, J. Korean Phys. Soc. 69, 893 (2016).

[3] M. Benedikt, D. Schulte, and F. Zimmermann, Optimizing integrated luminosity of future hadron colliders, Phys. Rev. ST Accel. Beams 18, 101002 (2015).

[4] P. Lebrun and L. Tavian, Beyond the Large Hadron Collider: A first look at cryogenics for CERN future circular colliders, 25th International Cryogenic Engineering Conference and the International Cryogenic Materials Conference in 2014, ICEC 25-ICMC 2014 (2014)., Beyond the Large Hadron Collider: A First Look at Cryogenics for CERN Future Circular Colliders, Phys. Procedia 67, 768 (2015).
[5] L. Tavian, Cryogenics overview, FCC Week 2016, Roma, 14, 2016.

[6] Witzenmann-Expansion Joint Manual, mieszków, http:// www.witzenmann-sachsen.de/repo/assets/Expansion\%20 joint\%20manual\%201501uk_5_12_12_20_download.pdf.

[7] L. Cadwallader, Vacuum Bellows, Vacuum Piping, Cryogenic Break and Copper Joint Failure Rate Estimates for ITER Design Use (Idaho National Laboratory, 2010).

[8] T. Edamitsu, S. Yamamoto, M. Ujita, T. Yamakawa, S. Kishimoto, K. Nakamura, and K. Yamamoto, Realization of Invar alloy LNG piping, in Proceedings of 22nd World Gas Conference (2003).

[9] http://cryogenics.nist.gov.

[10] S. Claudet, G. Ferlin, F. Millet, E. Roussel, and J. P. Sengelin, Two $100 \mathrm{~m}$ Invar $^{\circledR}$ transfer lines at CERN: Design principles and operating experience for helium refrigeration, in Proceedings of the 20th International Cryogenic Engineering Conference, ICEC20, 2006, Chap. 248 (web) or pp. 1047-1050 (book).

[11] G. Ambrosio, T. G. Anderson, and N. Andreev et al. (VLHC Design Study Group Collaboration), Design study for a staged very large hadron collider, Conference No. C0106-30, Reports No. SLAC-R-591, No. SLAC-R-0591, No. SLAC-591, No. SLAC-0591, and No. FERMILABTM-2149.

[12] A. Thakkar and M. I. Vyas, Design and Analysis of Bellows Free Cryogenic Transfer Line, International Conference on Current Trends in Technology "NUiCONE-2011," Institute of Technology (Nirma University, Ahmedabad-382 481, 2011).

[13] L. C. Cadwallader, Cryogenic System Operating Review for Fusion Application (Idaho National Engineering Laboratory, 1992). 